\title{
An analysis of print sizes of South African newspapers in relation to prescription of reading devices for low vision patients
}

\section{AO Oduntan*}

Optometry Department, University of Limpopo, Private Bag x1106, Sovenga, 0727 South Africa <alabio@unorth.ac.za>

\section{Abstract}

One of the aspirations of many low vision patients is to read newspapers. Many low vision practitioners use $1 \mathrm{M}$ print (Snellen equivalent $6 / 15$ at $40 \mathrm{~cm}$ or $6 / 24$ at $25 \mathrm{~cm}$ ) as the benchmark for prescribing low vision optical devices for patients who wish to read newspapers. There are certain sections of the newspapers, however, with print sizes that are smaller than $1 \mathrm{M}$, therefore prescriptions based on $1 \mathrm{M}$ print size may present difficulties to the patient. The purpose of this study was to measure the smallest print sizes of selected sections of South African newspapers. Based on the print size values, advice could be provided for effective prescription of reading devices for low vision patients whose desire is to read all or specific sections of newspapers.

Print sizes in eight sections of 38 South African newspapers were measured using a $7 \mathrm{x}$ measuring magnifier with graticle. The smallest print sizes in the various sections of the newspapers ranged from $0.6 \mathrm{~mm}$ or $0.4 \mathrm{M}(6 / 9.5$ at 25 $\mathrm{cm}$ or $6 / 6$ at $40 \mathrm{~cm})$ to $1.9 \mathrm{~mm}$ or $1.3 \mathrm{M}(6 / 30$ at $25 \mathrm{~cm}$ or $6 / 20$ at $40 \mathrm{~cm})$. The mean sizes of the various sections of the newspapers ranged from $0.7 \pm 0.18 \mathrm{M}$ for the advert section to $1.12 \pm$ $0.07 \mathrm{M}$ in the news section.

Reading device magnification established by using $1 \mathrm{M}$ print size as benchmark for prescribing reading aids for low vision patients may not afford the visual capability needed to read all sections of a newspaper. Such patients, thus may experience difficulty when reading certain sections of newspapers. There is therefore, a need for low vision practitioners to have a specific knowledge of the print sizes of the section of newspapers that the patient wants to read and prescribe for them accordingly.

Keywords: Newspaper, print size, South Africa, low vision patients, low vision practitioners.

\section{Introduction}

Reading has been established as one of the most frequently reported reasons by patients, for seeking low vision aids ${ }^{1}$. Visual acuity values are often used in calculating powers of reading devices for low vision patients. The near acuity values are particularly important in prescribing magnifying devices for reading at near and have been used extensively in the estimation of magnification required by low vision patients ${ }^{2-8}$. The concept of visual acuity, especially at near is becoming quite complex because of the various notations that are available in the literature. It is therefore, necessary to briefly describe these various notations and their inter-conversions before discussing their use in prescribing near devices for low vision patients.

In clinical settings, near visual acuity value is usually specified in point (N), M, Snellen equivalent or $\log$ MAR notation. Point terminology of specification of print size derives from the old

*BOptom (Hons) PhD

Received 11 November 2004; revised version accepted 17 June 2005 
method used by printers to specify the slug or metal block on which raised print was embossed ${ }^{9}$. The term point (1/72 inch or approximately $0.353 \mathrm{~mm}$ ) is useful because it specifies (to a first approximation), the absolute size of print, and is often given by publishers on the 'cataloguing in publication' page of a book, after the title page ${ }^{9}$. A measure of visual acuity based on point size was developed by British ophthalmologists in the nineteen fifties ${ }^{10,11}$ and named ' $\mathrm{N}$ ' notation, so that point and $\mathrm{N}$ units can be used interchangeably. One major difficulty arising from the use of point terminology, however, is that different styles of print of a given point size will have loop heights (letter heights) of slightly different dimensions ${ }^{9}$.

An ophthalmic specification of near visual acuity in $\mathrm{M}$ notation was introduced to the low vision field as a convenient specification of print sizes and $1 \mathrm{M}$ (equivalent to $\mathrm{N} 8$ or 8 point) was defined as a print size (approximately $1.45 \mathrm{~mm}$ ) for which the lower-case letter height subtends 5 minutes of arc at a viewing distance of one meter $^{12}$. The angular subtense, therefore, is equivalent to that of a $6 \mathrm{~m}$ or 20 feet distance acuity letter viewed at 6 meters or 20 feet. Use of point and $\mathrm{M}$ units are preferred for specification of near visual acuity because they express a fixed print size viewed at a specific distance ${ }^{9}$. M notation is useful in calculating the dioptric power of reading devices and the viewing distances for low vision patients. For example, if a person with low vision reads best with $4 \mathrm{M}$ at $25 \mathrm{~cm}$ and it is anticipated that the goal print size is $1 \mathrm{M}$, the latter print size would have to be placed at $25 / 4=6.5 \mathrm{~cm}$ to be read and would require a $1 / 0.0625=16 \mathrm{D}$ lens or accommodation or both to read the print.

The $\log$ MAR notation was introduced by Bailey and Lovie in 1976. It was based on geometric progression of $10 \sqrt{10}$ or 1.2589 letter sizes $^{13}$ and is now of great value in low vision care because the systematic optotype size progression ratio can greatly facilitate the various predictions and calculations that clinicians may wish to make when prescribing magnifiers for distance or near vision ${ }^{9} 13,14$. For a particular print size read by a person with low vision on a $\log$ MAR reading chart; reducing the viewing distance by a certain ratio produces a proportionate improvement of print size that can be read by the person. A reduction in print size by a half, or a quarter for instance will enable the patient to read twofold or four-fold smaller prints respectively. This will, however, require a $2 \mathrm{x}$ or $4 \mathrm{x}$ dioptric power respectively to read. For example, if a presbyopic person with low vision using +2.50 addition has threshold reading acuity of 20 point at $40 \mathrm{~cm}$ on a $\log$ MAR chart, which is practically equivalent to $2.4 \mathrm{M}(6 / 38)(20 / 125)(0.8 \log \mathrm{MAR})$, and the practitioner estimates the required goal print size to be 8 point (1 M) (6/15) (20/50) (0.3 logMAR). This will require a four-fold improvement in vision as there are four logMAR steps from 20 point to 8 point. Therefore, if the working distance is reduced by four logMAR steps (from 40 $\mathrm{cm}$ to $16 \mathrm{~cm}$ ), the patient will be able to read the desired print. Viewing at $16 \mathrm{~cm}$ requires $+6.25 \mathrm{D}$ system in the form of accommodation or optical device or both.

One of the advantages of the logMAR principle is that various near VA notations can be inter-converted as described by Johnston ${ }^{9}$ when a $\log$ MAR acuity test chart is used. For example, $1 \mathrm{M}$ is equivalent to 8 point or $\mathrm{N} 8$, hence point sizes can be converted to $\mathrm{M}$ units by dividing the value by 8 . Also, when testing near VA at $25 \mathrm{~cm}$, the denominator of the equivalent metric Snellen fraction is obtained by multiplying the point size by 3 (for example, $\mathrm{N} 8$ at $25 \mathrm{~cm}=6 / 24$ ), and the denominator of the equivalent imperial Snellen fraction is obtained by multiplying the point size by 10 (for example, N8 at $25 \mathrm{~cm}=20 / 80$ ). When testing at $40 \mathrm{~cm}$, the point acuity can be converted to the metric Snellen equivalent by multiplying by 1.9 (approximately 2). For example, $\mathrm{N} 24$ at $40 \mathrm{~cm}=6 / 48$ and conversion into the equivalent imperial Snellen fraction is done by multiplying the next largest point size on the chart by 5 (for example, N24 at $40 \mathrm{~cm}=32 \times 5$ $=160$ or $20 / 160)$.

One of the major functional consequences of low vision is difficulty in reading at near and far. Many patients want to be able to read personal 
letters; others are interested in reading labels on items in the shop or read street names or house numbers. There are many low vision patients whose desire, however, is to be able to read newspapers; each patient having different reasons for wanting to do so. Many want to keep up with the news, some are interested in television programs, some want to follow stock investments, some want to complete crossword puzzles, and others want to check the obituaries ${ }^{15}$. No matter what the purpose of reading is, it has been emphasized that determination of appropriate print size is critical for optimizing reading efficiency for patients with low vision ${ }^{16}$. In recognizing the importance of reading tasks for low vision patients, various aspects of this function such as print size requirement ${ }^{16}$ and reading speed ${ }^{17}$ have been investigated by various authors.

The ability to read the newspapers plays a central role in the evaluation and rehabilitation of people with low vision ${ }^{15}$. Presumably, in recognition of the importance of reading newspapers to low vision patients, low vision has been defined by Legge ${ }^{18}$ as inability to read the newspaper at normal reading distance of 40 centimeters with best optical correction. Optometrists and ophthalmologists in America have reported that individuals with best corrected visual acuity of $6 / 18$ or worse cannot read newspapers ${ }^{19}$ suggesting that visual acuity of $6 / 15$ or better is needed to read newspapers. $1 \mathrm{M}$ print size has been considered to be benchmark for successful rehabilitation of reading $5,7,20-23$, and many low vision practitioners use this value in the prescription of reading magnifiers for low vision patients whose desire is to read newspapers. $1 \mathrm{M}$ ( 8 point) is equivalent to $6 / 24(20 / 80)(0.6 \log \mathrm{MAR})$ if the print is read at 25 centimeters and is equivalent to $6 / 15(20 / 50)(0.4 \log$ MAR $)$ if the print is read at 40 centimeters $^{9}$ and has been considered to be the standard size for newspapers ${ }^{9,24}$. The Keeler A series near vision chart has a wide range of print sizes and shows the magnification required to improve visual acuity to N8 (1M) which is considered to be the average print sizes in newspapers and magazines ${ }^{24}$. A research study ${ }^{15}$ has established that the use of $1 \mathrm{M}$ as a standard print size is inappropriate for American newspapers. Recognizing the inadequacy of $1 \mathrm{M}$ representation of newspaper print sizes, the author of the present article uses print sizes ranging from $0.5 \mathrm{M}$ (4 point) $(6 / 12$ or $20 / 40)$ to $0.4 \mathrm{M}(6 / 9$ or $20 / 30)$ at $25 \mathrm{~cm}$ in prescribing devices for low vision patients who wish to read newspapers.

Although, 1M print size used as benchmark for reading newspapers by many authors and practitioners may represent the average print size in most newspapers, it is important to note that patients whose prescriptions are based on this average print size will not be able to read prints that are below average size. It is, therefore important for practitioners to know the distribution of print sizes in the local newspapers in order to be able to recommend the appropriate low vision devices relative to the section of the newspaper that the patient wants to read. The purpose of this study therefore, was to critically analyze print sizes in the various sections of the South African newspapers and establish their relationship with $1 \mathrm{M}$ print.

\section{Methods}

Thirty eight newspapers (national, provincial and community) from different towns and cities of South Africa were randomly collected for this study and relevant measurements were made. Eight sections of the papers (news, adverts, sport, stock/ equity, business/finance, television guide, weather and crossword puzzles) were targeted. These are the most common sections of the newspapers. In each section, two areas with the smallest print sizes were randomly selected for study. The heights of the lower case ' $o$ ' in the smaller print were measured to the nearest $0.1 \mathrm{~mm}$ using a $7 \mathrm{x}$ measuring magnifier with graticle (Bausch and Lomb). Three measurements were made and an average taken, and where they differed by more than $0.1 \mathrm{~mm}$, the average of the two nearest values was recorded. The smallest print sizes were recorded and subsequently converted to $\mathrm{M}$ units by dividing by 1.45 $\mathrm{mm}$. The $\mathrm{M}$ values for the various sections of the newspaper were analyzed and presented in Table 1 . For practical purposes, the $M$ values of print sizes 


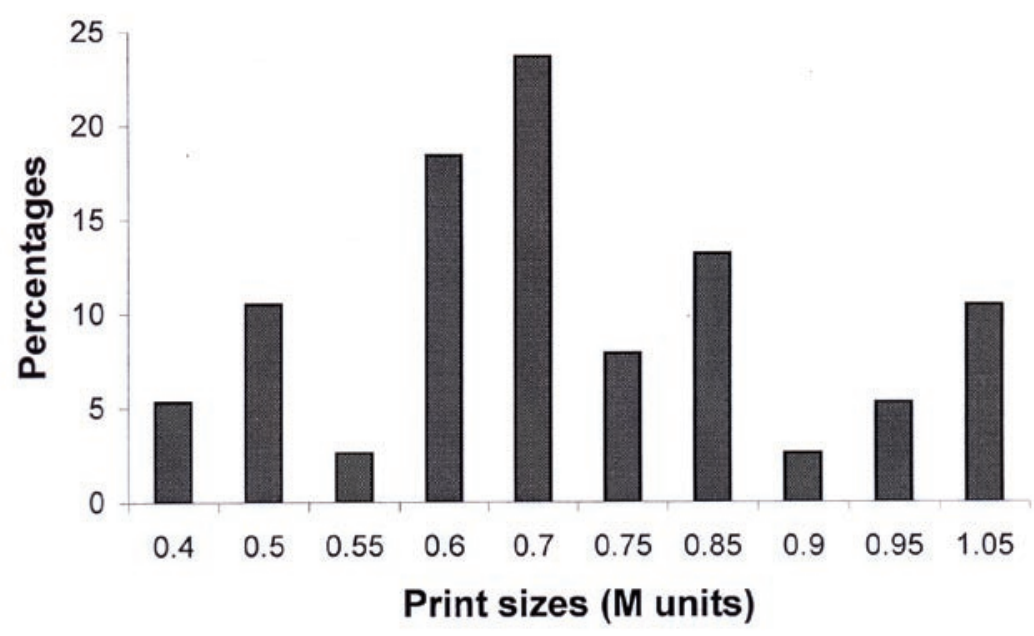

Figure 1. Distribution of print sizes in the advert sections of the newspapers. There is a wide variation of print sizes in this section of the newspapers. The most common sizes were $0.6 \mathrm{M}$ and $0.7 \mathrm{M}$.

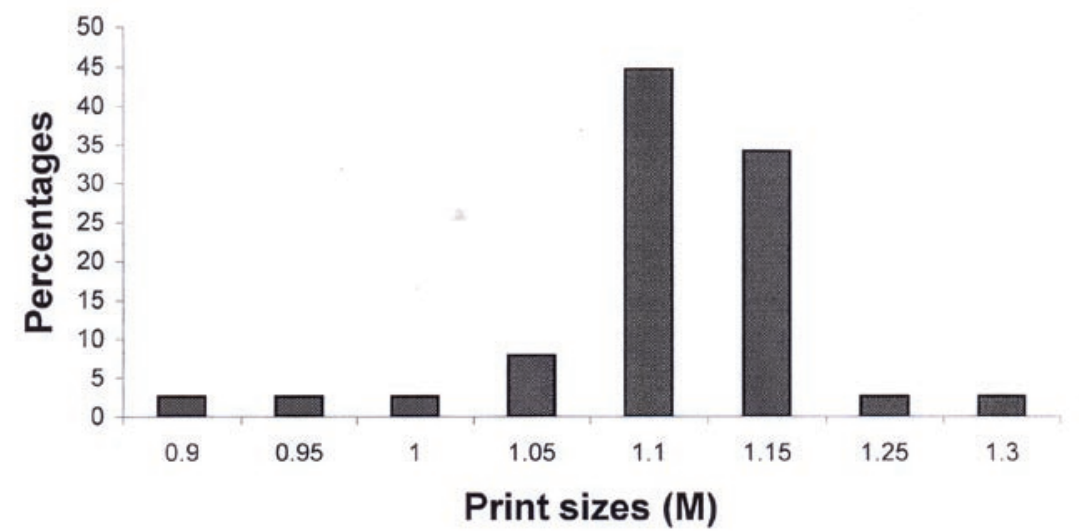

Figure 2. Distribution of print sizes in the news section of the newspapers. Most of the print sizes in this section of the newspaper were between $1.1 \mathrm{M}$ and $1.15 \mathrm{M}$.

were rounded off in 0.05 steps and utilized in Table 2 and Figures 1 and 2.

\section{Results}

Sections featured in the newspaper vary from one paper to another. Of the eight sections studied, only two, (news and adverts) were present in all the newspapers. Reports of sports were present in $37(97.37 \%)$ of the newspapers). Weather reports were the least common, occurring in only nine $(23.68 \%)$ of the newspapers examined. The smallest print size in the study was $0.60 \mathrm{~mm}(0.40 \mathrm{M})$, corresponding to Snellen acuity of 6/9.5 (20/32) or $0.2 \log$ MAR at $25 \mathrm{~cm}$. This corresponds to $6 / 6$ $(20 / 20)$ or $0.0 \log$ MAR at $40 \mathrm{~cm}$. The largest of the print sizes measured was $1.90 \mathrm{~mm}(1.30 \mathrm{M})$ corresponding (approximately) to Snellen 6/30
(20/100) or $0.7 \log$ MAR at $25 \mathrm{~cm}$ or $6 / 2020 / 63$ or $0.5 \log$ MAR at $40 \mathrm{~cm}$. The difference between the smallest and the largest print size (M) measured in terms of magnification was $3.25 \mathrm{x}$. The largest of the print sizes measured were in the news sections, while the smallest were in the advert sections. The most common print size in the news section was $1.1 \mathrm{M}$ as shown in Figure 2, whereas the most common print size in the advert section was $0.7 \mathrm{M}$. The magnification gradient of the smallest print sizes (magnification ratio) in the news and adverts sections were approximately $1.5 x$ and $2.63 x$ respectively.

The range, mean, standard deviation and other parameters of the print sizes are shown in Table 1. Due to the skewness of the data in some of the sections, (for instance, news section skewness $=0.47$; kurtosis $=3.48$ ); median, 25th and 75th percentiles were presented to provide a greater representative picture of the data. The distribution of the various print sizes (percentages) in the various sections of the newspapers in relation to $1 \mathrm{M}$ acuity notation is shown in Table 2 . In the advert section, the prints were usually less than $1 \mathrm{M}$ (Figure 1), whereas, in the news section, the print sizes were generally equal to or greater than $1 \mathrm{M}$ (Figure 2). A comparison of the print sizes in the South African and American newspapers ${ }^{15}$ is shown in Table 3.

\section{Discussion and conclusion}

Differences in the print sizes of reading material may present serious problems to persons with low vision, should the print contain sizes that the visual capacity afforded by their optical devices cannot resolve. As newspapers contain various sections with varying print sizes, the rational behind the recommendation of $1 \mathrm{M}$ print size as a benchmark for prescribing low vision reading 
Table 1: The various sections of the newspapers measured, $\mathrm{N}$ is the number of newspapers which feature the sections indicated. Range, mean and standard deviation, median, 25th, 75th percentiles and inter-quarter percentiles of the print sizes in $\mathrm{M}$ units are shown. The mean and median values were similar except in the stock and equity sections.

\begin{tabular}{|c|c|c|c|c|c|c|c|c|}
\hline \multirow[t]{2}{*}{ Newspaper section } & \multirow[t]{2}{*}{$\mathbf{N}$} & \multicolumn{6}{|c|}{ Print sizes $(M)$ of the newspaper sections } & \multirow{2}{*}{$\begin{array}{l}\text { Inter- } \\
\text { quartile } \\
\text { Range }\end{array}$} \\
\hline & & Range & Mean & SD & Median & $\begin{array}{l}25 \text { th } \\
\text { perc. }\end{array}$ & \begin{tabular}{|l} 
75th \\
Perc.
\end{tabular} & \\
\hline News & 38 & $0.9-1.3$ & 1.12 & 0.07 & 1.10 & 1.10 & 1.17 & 0.07 \\
\hline Classified adverts & 38 & $0.4-1.04$ & 0.70 & 0.18 & 0.69 & 0.62 & 0.83 & 0.21 \\
\hline Sports & 37 & $0.69-1.30$ & 0.96 & 0.16 & 0.90 & 0.83 & 1.10 & 0.27 \\
\hline Stock/ equities & 18 & $0.55-1.20$ & 0.82 & 0.19 & 0.43 & 0.69 & 0.97 & 0.28 \\
\hline Business/ Finance & 27 & $0.62-1.3$ & 0.99 & 0.21 & 1.07 & 0.81 & 1.17 & 0.36 \\
\hline Television & 19 & $0.69-1.17$ & 1.01 & 0.12 & 1.04 & 0.90 & 1.10 & 0.20 \\
\hline Weather & 9 & $0.62-1.10$ & 0.81 & 0.18 & 0.83 & 0.62 & 0.94 & 0.32 \\
\hline Crossword/ puzzles & 11 & $0.83-1.17$ & 1.03 & 0.10 & 1.04 & 0.97 & 1.04 & 0.07 \\
\hline
\end{tabular}

Table 2: Percentages of print sizes in $M$ units for the various sections of the newspapers that were greater or equal to $1 \mathrm{M}$ and those less than $1 \mathrm{M}$. The news sections were mostly $1 \mathrm{M}$ in size, but only $22.22 \%$ of the stock and equity and $11.1 \%$ of the weather sections were printed in $\geq 1 \mathrm{M}$ equivalents.

\begin{tabular}{|l|l|l|}
\hline Newspaper section & $\mathbf{\%} \geq \mathbf{1 M}$ & $\mathbf{\%}<\mathbf{1 M}$ \\
\hline News & 94.74 & 5.26 \\
\hline Classified adverts & 13.16 & 86.84 \\
\hline Sports & 40.54 & 59.45 \\
\hline Stock/Equity & 22.22 & 77.78 \\
\hline Business/Finance & 62.96 & 37.04 \\
\hline Television & 63.16 & 36.84 \\
\hline Weather & 11.10 & 88.89 \\
\hline Puzzle & 72.73 & 27.27 \\
\hline
\end{tabular}

devices is questionable. There were many sections of the South African newspapers, where the print sizes were significantly smaller than $1 \mathrm{M}$, hence, the patient will not be able to read them with a magnifier prescribed based on $1 \mathrm{M}$ reading print. For instance, although in most newspapers, $94.74 \%$ of the smallest sizes were $1 \mathrm{M}$ or larger, there were a few newspapers $(5.26 \%)$ where prints sizes of this section were less than $1 \mathrm{M}$. Should a patient have his or her prescriptions based on $1 \mathrm{M}$ print size, he or she will not be able to resolve the
Table 3: A comparison of the South African (present study) and American ${ }^{15}$ range of newspaper print sizes (M). The smallest sizes in each section of the South African newspapers were mostly smaller than the corresponding American values.

\begin{tabular}{|l|c|l|}
\hline $\begin{array}{l}\text { Newspaper } \\
\text { section }\end{array}$ & $\begin{array}{l}\text { Range (M) } \\
\text { S. African }\end{array}$ & $\begin{array}{l}\text { Range (M) } \\
\text { American }\end{array}$ \\
\hline News & $0.9-1.30$ & $1.03-1.31$ \\
\hline $\begin{array}{l}\text { Classified } \\
\text { Adverts }\end{array}$ & $0.4-1.04$ & $0.69-1.03$ \\
\hline Sports & $0.69-0.83$ & $0.69-0.96$ \\
\hline Stock/Equity & $0.55-1.20$ & $0.69-0.89$ \\
\hline Television & $0.69-1.17$ & $0.83--1.31$ \\
\hline Weather & $0.62-1.10$ & $0.76-1.38$ \\
\hline Puzzle & $0.83-1.17$ & $1.03-1.65$ \\
\hline
\end{tabular}

smaller print sizes or may have to take the trouble of reducing the reading distance to generate greater magnification, provided that he or she has enough accommodation to support this. Such a patient will have difficulty in reading or will be unable to read $77.78 \%$ or $88.90 \%$ of the stock/equity and weather respectively (Table 2). Compared with the American print sizes ${ }^{15}$, the South African newspaper print size values were either similar or slightly smaller (Table 3). The findings in this study agree with that of DeMarco and Massoff ${ }^{15}$ that, $1 \mathrm{M}$ 
size cannot be used as a standard for recommending low vision devices, and that there is no substitute for knowing the specific section of the newspaper that a person with low vision wishes to read as there is no standard newsprint size. Also, this agrees with the views expressed by Lueck ${ }^{25}$ that the best current practice for assessment and intervention to promote vision use should be integrated into functional activities or routinely determined primarily by the patient.

It was of interest to note that the smallest print size in the South African newspapers was $0.4 \mathrm{M}$, which corresponds to Snellen 6/6 (20/20) or logMAR 0.0 at $40 \mathrm{~cm}$. This implies that, a patient with normal vision, who wishes to read sections of the newspapers with such print sizes, must have visual acuity of $6 / 6(20 / 20)$ or better at $40 \mathrm{~cm}$ or its equivalent at other reading distances. Where the best (uncorrected or corrected) near visual acuity of the patient is below this level, it is necessary to advice the pre-presbyopic patient to move the print closer to generate some magnification and the presbyopic patient to have his near add adjusted for a closer viewing distance. Where accommodation status is very low, patient may be advised to try magnifiers, when necessary.

Other than print sizes, there are factors such as acuity reserve which need to be considered when prescribing optical devices for the purpose of reading newspapers. Acuity reserve (also called resolution reserve) for individual readers has been expressed as a ratio between the size of the smallest print that can be read with the best efficiency or comfort and the size of the smallest print that can be read at all ${ }^{16}$. A low vision patient who is only interested in checking the weather, stock/ equity, or television guide (spot reading) will need the optical aid, just to be strong enough to enlarge the print to the threshold size level. A patient who desires to read the news, or sport section (fluent reading), however, will require greater amount of magnification for acuity reserve. The threshold magnification provided compensates for reduced visual acuity, while the reading rate would be improved systematically with increased magnification $^{26,27}$. It has been estimated that spot read- ing requires only half the magnification needed for fluent reading ${ }^{24}$. It follows, therefore, that a patient who requires a magnifier for spot reading of a section of newspaper with print size $1 \mathrm{M}$ $(6 / 24)$ at $25 \mathrm{~cm}$ or $6 / 15$ at $40 \mathrm{~cm}$ will require twice the power of magnifier for the same print sizes at the same distances for fluent reading. Similarly, a patient who needs to read $1 \mathrm{M}$ print fluently will have to be tested with $0.5 \mathrm{M}(6 / 12)$ at $25 \mathrm{~cm}$ or $6 / 7.5$ at $40 \mathrm{~cm}$ reading distance. Legge et al ${ }^{26}$ has proposed that low vision patients need print size that is five times threshold size and that with magnification providing this, five characters in the field of view were sufficient to read at maximum or near-maximum reading rate. This means that a patient who needs to read $6 / 24$, would need to be tested with a $6 / 5$ print for fluent reading. Conversely a patient who needs a $2 \mathrm{x}$ magnification for threshold reading will need to be provided with 10x magnification for maximum reading rate for the same print size.

Recognizing the fact that research findings do not usually translate directly to clinical operatives and also, that increase magnification reduces visual field, the relative advantages of magnification and visual field reduction should always be taken into consideration when prescribing low vision reading aids relative to the desire of the patient. It is recommended that the minimum magnification that enables the patient to read the smallest print of the newspaper or any other print fluently, at the same time providing the greatest visual field be prescribed for patients.

In conclusion, print sizes in newspaper vary significantly and the concept of employing $1 \mathrm{M}$ as benchmark for calculating the prescription for reading devices for low vision patients is not advisable. Low vision devices based on smaller print sizes such as $0.4 \mathrm{~m}(6 / 9)(20 / 30)$ or $0.5 \mathrm{M}$ $(6 / 12)(20 / 40)$ at $25 \mathrm{~cm}$ may enable the patient to read a large proportion or all the print sizes in South African newspapers. It is, however, recommended that, where possible, prescription should be based on the actual print sizes that the patient wants to read, with consideration for acuity reserve and best field of view. 


\section{Acknowledgement}

I wish to express my thanks to current and ex-students of the University of the Limpopo, and colleagues from other Universities in South Africa who assisted with collection of newspapers. Financial support from the University of the Limpopo, South Africa is acknowledged.

\section{References}

1. Stelmack JA, Rosenbloom AA, Brenneman CS, Stelmack TR. Patients' perceptions of need of low vision devices. $J$ Vis Imp Blind $200397521-516$.

2. Fonda G. Management of low vision. New York: Thieme-Stratton, 1981.

3. Jose RT. Understanding low vision. New York: American Foundation for the Blind, 1983.

4. Faye EE. Evaluating near vision: The Amsler grid and field defects. In: Faye EE, ed. Clinical low vision, 2nd ed. Boston: Little and Brown, 1984 pp 45-60.

5. Lovie-Kitchin JE, Bowman KJ. Senile Macular degeneration - management and rehabilitation. Boston: Butterworth, 1985.

6. Bailey IL, Lovie JE. Design and use of a new near chart. Am J Optom Physiol Opt 198057 378-387.

7. Cole RG. Predicting the low vision reading add. J Am Optom Assoc 199364 19-27.

8. Wolffsohn JS, Eperjesi F. Predicting prescribed magnification. Ophthal Physiol Opt 200424 334-338.

9. Johnston AW. Making sense of the M, N and logMAR system of specifying visual acuity. Problems in Optom 1991 3 394-107.

10. Law FW. Standardized of reading types. $\mathrm{Br} J$ Ophthalmol 195135 765-737.

11. Law FW. Reading types. $\mathrm{Br} J$ Ophthalmol 195236 689-690.

12. Sloan LL. New test chart for measurement of visual acuity at far and near distances. $\mathrm{Am} \mathrm{J}$ Ophthalmol 195948 807-813.

13. Bailey IL, Lovie JE. New design principles for visual acuity letter charts. Am J Optom Physiol Opt 197653 740-745.

14. Bailey IL, Lovie JE. The design and use of a new near vision chart. Am J Optom Physiol Opt 198057 378-387.

15. DeMarco LM, Massof RW. Distribution of print sizes in U.S. Newspapers. J Vis Imp Blind 1997 91 9-13.

16. Lueck HA, Bailey IL, Greer RB, Tuan KM, Bailey VM, Dornbusch HG. Exploring print size requirements and reading for students with low vision. J Vis Imp Blind 200397 335-354.

17. Gompel M, Van Bon WHJ, Schreuder R. Reading by children with low vision. J Vis Imp Blind 200498 77-89.

18. Legge GE. Three perspectives on low vision reading. Optom Vis Sci 199168 763-769.

19. Linhaas M. A national survey of ophthalmologists, optometrists, rehabilitation and education professionals on low vision and blindness. Optom Vis Sci 199269 31-34 (suppl.).

20. Sloan LL. Reading aids for the partially sighted: A systematic classification procedure for prescribing. Baltimore: William and Wilkins, 1977.

21. Carter K. Comprehensive preliminary assessment of low vision. In RT Jose (Ed) Understanding low vision. New York: American Foundation for the Blind, 54-104 1983.

22. Fonda G. Management of the patient with subnormal vision. 2nd ed. St Louis: CV Mosby, 1970.

23. Nowakowski RW. Assessment of visual acuity. In: Nowakowski RW, Primary low vision care. Norwalk: CT Appleton \& Lang, 1994 37-45.

24. Bower J. Practical guide to low vision assessment and dispensing. Optometry Today Feb 9 2001 34-36.

25. Lueck AH. Relating functional vision assessment, intervention, and outcomes for students with low vision. Vis Imp Res 20046 45-52

26. Legge GE, Rubin GS, Pelli DG, Schleske MM. Psychophysics of reading II. Low Vision. Vision Res 198525 253-266.

27. Lovie-Kitchin, JE, Woo GC. Effect of magnification and field of view on reading speed using a CCTV. In: Woo, G (ed) Low Vision: principle and applications. New York: SpringerVerlag, 308-322. 1987. 